\title{
As formas de comunicação pedagógica "midiatizada": 0 socioeducativo e o didático*
}

Daniel Peraya**

\begin{abstract}
RESUMO: O autor analisa os conceitos principais descrevendo diferentes tipos de comunicação pedagógica "midiatizada". Ele tenta demonstrar que o conceito do discurso parece ser um dos mais importantes para se analisar estas formas de comunicação pedagógica "midiatizada". Distingue duas formas principais que podem ser consideradas como pólos de uma taxonomia e caracteriza cada uma delas pelas suas características principais relacionadas a conteúdo; objetivos; público-alvo; currículo, avaliação; cenário de interação social; referências material, humana, institucional e sociocultural etc. Finalmente, ele mostra que este tipo de distinção é um modo para se dar diretriz à comunicação "midiatizada" com base em capacitação e ensino.
\end{abstract}

Palavras-chave: comunicação midiatizada, comunicação pedagógica, discurso, semiótica

Considerar os processos de ensino, as práticas educativas, como fatos, como atos comunicativos pode parecer evidente e relevar do simples bom senso: "Ensinar tem um sentido muito próximo de comunicar", escreve Vandevelde (1982). As comunicações educativa e/ou pedagógica correspondem a usos particulares de linguagens, de sistemas de comunicação conhecidos e estudados em outros contextos. Mais precisamente, a comunicação pedagógica apresenta-se como um sistema heterogê-

* Artigo traduzido por Alain P. François.

** TECFA (Technologies de Formation et d'Apprentissage), Faculté de Psychologie et des Sciences de l'Education, Université de Genève, Suíça. 
neo, mesclando formas de expressão bem diferentes. Por exemplo, uma seqüência de ensino pode apresentar a seguinte continuidade: uma exposição oral, o emprego de uma lousa, a projeção comentada de slides, a análise de documentos gráficos impressos, uma exposição oral etc.

\section{Comunicação pedagógica e comunicação "midiatizada"}

Nessa diversidade, os pesquisadores, em geral, distinguem:

1. a comunicação verbal: o docente usa a fala; o veículo fundamental da educação e da formação continua sendo a linguagem verbal, sob suas formas falada ou escrita;

2. a comunicação analógica: quando fala, o docente muda de tom, modula suas inflexões vocais, mexe-se, desloca-se. Portanto, o docente utiliza com fins expressivos e comunicativos um número importante de indicações não-lingüísticas em sentido estrito que os alunos - os destinatários - não têm a menor dificuldade em interpretar. Trata-se, por exemplo, de variáveis entonativas e supra-segmentais da língua oral (entoação, curva melódica da voz, ritmo da fala etc.), de atitudes corporais (o "mímico-postural"), da ocupação do espaço que a proxémica estuda etc.

3. A comunicação áudio-escrito-visual: o docente lança mão, com freqüência, de documentos sonoros e/ou visuais (esquemas e gráficos, fotos, slides, cinema ou vídeo) ou ainda de programas informáticos (softwares e multimídia).

\section{Comunicação "midiatizada" e dispositivo tecno-semiótico}

Se a linguagem verbal continua sendo o principal suporte do ensino, o uso de outros modos de representação - outras tecnologias intelectuais - tende a generalizar-se.

Essa designação se desenvolveu sob o impulso das correntes cognitivistas, principalmente na esteira da informática e da inteligência artificial. No entanto, o conceito em si não é nenhuma novidade. De fato, é 
inspirado no de ferramenta cognitiva que podemos fazer remontar, por exemplo, aos trabalhos de Cassirer sobre as formas simbólicas, sobre o homem "animal simbólico": as formas simbólicas devem ser consideradas como formas de objetivação do real, estruturando nossos conhecimentos e guiando nossas ações. Mais perto de nós, podemos também citar as pesquisas de Godoy que evidenciaram os efeitos da escrita, e depois da imprensa, sobre os modos de pensamento e de intelecção do real. De fato, a escrita determinou a emergência de uma forma de racionalidade, de lógica e de objetividade da qual o "efeito-lista" constitui um excelente exemplo. As tecnologias intelectuais contribuem, portanto, "para determinar o modo de percepção e de intelecção pelo qual conhecemos os objetos. [Elas] fornecem modelos teóricos para nossas tentativas de conhecer a realidade". Elas são ferramentas cognitivistas tal como "os sistemas técnicos, as diversas línguas naturais e formais, os sistemas gráficos, os sistemas plásticos da arte, os sistemas abstratos como a lógica ou os sistemas de classificação, e, finalmente, last but not least, os sistemas de conceitualização e de saber, científicos ou filosóficos". Esses diferentes sistemas têm em comum a capacidade e a função de representar a experiência, de nomeá-la, mas, também, de constituí-la como tal para torná-la identificável, pensável, manipulável e comunicável. Ou seja, eles são o instrumento de nossas interações com o universo: "Sua função é uma função de mediação pela qual a relação entre o homem e o mundo, em suas diversas modalidades, constrói-se."

Posto isso, no quadro deste texto, concentraremos nossa atenção sobre a comunicação áudio-escrito-visual freqüentemente designada pelo termo de comunicação midiatizada. Isso significa que esses modos de comunicação utilizam dois tipos de midiatização. Por um lado, eles constituem uma forma particular de tratamento da informação, e é nesse sentido que os pedagogos às vezes falam em "midiatização dos conteúdos de ensino"; na realidade, seria provavelmente mais justo falar em "mediação" uma vez que não se pode comunicar um pensamento sem forma de representação. A própria linguagem natural constitui, aliás, uma forma de mediação, um "grau zero" da representação. Por outro lado, esses sistemas semióticos precisam de um certo número de operações técnicas tanto para sua produção quanto para sua difusão. No caso do cinema, por exemplo, os dispositivos discursivos (a linguagem cinematográfica) e técnicos (as técnicas cinematográficas) "midiatizam" os conteúdos a serem transmitidos e concorrem para sua apresentação e estruturação. 
O reconhecimento dessas duas dimensões principais das mídias pedagógicas - um sistema semiótico de representações e um dispositivo tecnológico - permite definir o conceito de dispositivo tecno-semiótico.

Acrescentamos por fim que considerar as diferentes formas das linguagens áudio-escrito-visuais como tecnologias intelectuais não deixa de ter conseqüências sobre as práticas educativas que erguem a bandeira dessa corrente de pesquisas. Dentre os diferentes usos educativos das linguagens audiovisuais, há um que está diretamente implicado pela noção de tecnologia intelectual: o audiovisual como suporte específico do aprendizado. Trata-se, apoiando-se sobre a especificidade das formas de representação e do tratamento da informação dessas linguagens, de favorecer a aquisição de competências e aptidões cognitivas específicas. Em outras palavras, supõe-se que sistemas simbólicos diferentes poderiam desenvolver faculdades intelectuais diferentes porque, precisamente, instauram faculdades diferentes: não se trata portanto de passar um conteúdo, um saber disciplinar graças à mediação de um "auxiliar" áudio-escrito-visual, mas outrossim de favorecer competências cognitivas mais gerais, até fundamentais.

Os gêneros de discursos

Não podemos, no entanto, estudar os mecanismos de comunicação, quaisquer que sejam, sem nos referir à noção de discurso. De fato, a linguagem verbal, por exemplo, nunca constitui uma entidade homogênea. Instrumento social de comunicação e de interações entre os indivíduos, ela se diversifica e especifica em função dos usos e usuários para constituir gêneros de discursos (Bakhtin 1984).

Logicamente, devemos emitir a hipótese de que as formas de comunicações educativas se diversificam em função dos produtores e enunciadores, das características das diferentes práticas sociais, e dos lugares de interação social, ${ }^{1}$ que as originam. A cada tipo de condições de produção (produtores, lugar de interação, intenções etc.) - supondo, é claro, que sejam diferentes e suficientemente contrastadas - deveriam corresponder formas arquetípicas de discursos, identificáveis e reconhecíveis por, pelo menos, três tipos de características gerais: 
- temáticas: uma especialização dos temas e dos conteúdos, cada lugar de interação determinando seu próprio repertório referencial;

- formais: marcadores discursivos ou semióticos diferentes, isto é, um modo característico de utilizar certas unidades significantes ou de privilegiar o uso de umas delas em detrimento de outras;

- relacionais. ${ }^{2}$ um tipo de relação e o modo como esta se inscreve formalmente em certas comunicações.

Nossa experiência da comunicação educativa - baseada essencialmente em videogramas e material escrito-visual - confirma essa hipótese. Se analisarmos esse material sob esses três aspectos temático, formal e relacional - logo veremos que não há nada mais diferente, por exemplo, de um videograma de formação de empresa, do que um episódio de Il était une fois... la vie, aquela série de emissões televisivas de vulgarização científica dedicada ao corpo humano, ou ainda do que essas produções escolares realizadas no quadro de suas aulas por alunos de liceus: a linguagem verbal, o modo de interpelar o público, a montagem, as imagens, a trilha sonora e sua importância relativa, tudo neles é diferente.

As análises semióticas das formas de comunicação educativa evidenciaram algumas dessas características discursivas. Inúmeros filmes didáticos, por exemplo, parecem construídos sobre o modelo do discurso verbal, o tratamento fílmico, inspirado do modelo narrativo, não constituindo mais do que uma formalização secundária (Jacquinot 1977). Numa outra direção, podemos evidenciar alguns mecanismos semiopragmáticos em jogo nas comunicações áudio-escrito-visuais assim como seus efeitos cognitivos (Meunier e Peraya 1993): por exemplo, a organização fílmica a-centrada ou, pelo contrário, centrada sobre uma única personagem - a figura convencional do herói - que permite suscitar no espectador seja a reflexão, seja a simples adesão por identificação, de tipo egocêntrico ou sociocêntrico. Por outro lado, Jacquinot mostrou que a construção e a organização das estruturas fílmicas correspondiam a duas concepções, duas estratégias pedagógicas claramente diferenciadas:

- a pedagogia do produto que considera que os conteúdos de ensino constituem uma entidade conceitual pré-construída que basta transportar com um mínimo de perdas; 
- a pedagogia do processo que considera que a construção fílmica, o "texto fílmico", contribui para a elaboração dos conhecimentos (Jacquinot op. cit.).

Finalmente, há também diferenças importantes ligadas ao contexto cultural, às tradições educativas, às expectativas e às características psicossociais do público etc. Os estudos comparativos de videogramas de formação franceses, ingleses e holandeses deixam transparecer configurações nacionais cuja importância é freqüentemente muito mais fundamental do que se poderia imaginar à primeira vista: por exemplo, o recurso ao humor e o valor exemplar do erro - o contra-exemplo -, muito bem tolerados pela tradição anglo-saxônica, o são muito menos nos países francófonos. ${ }^{3}$

\section{0 socioeducativo e 0 didático}

Resumindo, observamos a existência de formas de discursos relativamente contrastadas dos quais o didático e o socioeducativo poderiam muito bem constituir os dois pólos. ${ }^{4}$ Além disso, a cada um deles corresponde um conjunto de características externas, não discursivas, ligadas aos lugares de interação social: por exemplo, as finalidades e metas educativas, as temáticas, os públicos, as formas de organização etc. A primeira, a comunicação sociopedagógica, diz respeito mais amplamente à educação para um certo tipo de problemas sociais ou ligados à vida social ao passo que a segunda, a didática, releva rigorosamente da vontade de instruir organizada num sistema de ensino ou de formação, qualquer que seja seu tipo.

Notemos que optamos por "didático" em vez de "pedagógico". De fato, dentre tantas definições, a palavra "didático" parece sistematicamente remeter a uma função de ensino, de instrução, e é quase sempre referida à metodologia de aprendizado de uma matéria, de uma disciplina. O didático implica sempre, portanto, conteúdos específicos, programas, testes de avaliação ou de certificação etc. A comunicação didática nos introduz, portanto, imediatamente no contexto e na realidade escolar que constituem seu lugar de desenvolvimento privilegiado.

A comunicação socioeducativa, por sua vez, constituiria uma forma de acompanhamento da vida social, e compreenderia ações muito menos sistemáticas, incidindo sobre assuntos menos ou não-escolares, sobre comportamentos ou conhecimentos indispensáveis à vida social (profissional e 
pessoal), em outras palavras, à integração harmoniosa do indivíduo na sociedade. Encarregar-se-ia, portanto, de temas tais como educação para a saúde (prevenção da Aids, luta contra o tabagismo etc.), a segurança nas estradas, a procura de um emprego (preparação para as entrevistas...) etc. Salientaremos, portanto, que a comunicação socioeducativa se inscreve em atividades educativas que incidem sobre aspectos sociais ou em ações sociais que têm objetivos educativos. O quadro abaixo resume as principais diferenças:

\begin{tabular}{|c|c|c|}
\hline & Comunicação socioeducativa & Comunicação didática \\
\hline Conteúdos & $\begin{array}{l}\text { Temas gerais participando da inte- } \\
\text { gração social, educação para com- } \\
\text { portamentos sociais }\end{array}$ & $\begin{array}{l}\text { Programas e currículos liga- } \\
\text { dos aos programas esco- } \\
\text { lares ou aos perfis profissio- } \\
\text { nais definidos pela empresa }\end{array}$ \\
\hline Finalidades & $\begin{array}{l}\text { Desenvolvimento pessoal e sociali- } \\
\text { zação ("cidadão do mundo") }\end{array}$ & $\begin{array}{l}\text { Formação certificante ou } \\
\text { eventualmente qualificante } \\
\text { (por ex., formação aguda } \\
\text { em empresa) }\end{array}$ \\
\hline Tipo de aprendizado & $\begin{array}{l}\text { Com dominante do saber ser e do } \\
\text { saber fazer }\end{array}$ & $\begin{array}{l}\text { Com dominante do saber e } \\
\text { do saber fazer }\end{array}$ \\
\hline $\begin{array}{l}\text { Obrigações } \\
\text { organizacionais }\end{array}$ & $\begin{array}{l}\text { Ações pontuais ou de duração de- } \\
\text { terminada: por ex., campanha de } \\
\text { sensibilização }\end{array}$ & $\begin{array}{l}\text { Organização sistemática de } \\
\text { "percursos", módulos, pas- } \\
\text { sarelas etc. }\end{array}$ \\
\hline Público & $\begin{array}{l}\text { Grande público, qualquer público, } \\
\text { às vezes público-alvo }\end{array}$ & $\begin{array}{l}\text { Sempre público-alvo em } \\
\text { função dos níveis, dos ci- } \\
\text { clos e dos currículos, mas, } \\
\text { com freqüência, heterogê- } \\
\text { neo na categoria }\end{array}$ \\
\hline $\begin{array}{l}\text { Estratégias de } \\
\text { comunicação }\end{array}$ & Com dominante informativa & $\begin{array}{l}\text { Com dominante da forma- } \\
\text { ção }\end{array}$ \\
\hline Avaliação & Inexistente, na maioria dos casos & $\begin{array}{l}\text { Sempre presente, organi- } \\
\text { zada em função das formas } \\
\text { e modalidades de aplicação } \\
\text { institucionalmente prescri- } \\
\text { tas (inclusive nas formas de } \\
\text { empresa: ligação com car- } \\
\text { reira, integração nos locais } \\
\text { de trabalho etc.) }\end{array}$ \\
\hline Certificação & Inexistente, na maioria dos casos & Imposta pela instituição \\
\hline
\end{tabular}




\section{Do modelo à realidade escolar}

Estabelecer essas distinções não responde apenas a uma intenção classificatória ou taxonômica. Se fosse o caso, o trabalho seria bastante vão. Sua primeira utilidade é de mostrar a correspondência entre as formas discursivas e as estratégias didáticas nele postas em obra. A segunda é de fazer emergir as particularidades e as obrigações ligadas aos lugares de interação social. Aprender a conhecer melhor essas diferentes linguagens - os fatores internos - e as condições iniciais de produção e de difusão - os fatores externos - corresponde, portanto, também a preparar-se para utilizar melhor os documentos aos quais se recorre.

A partir do momento em que se generalizou o uso familiar ou doméstico do videocassete, os docentes tomaram consciência da facilidade - da flexibilidade - da possibilidade de reassistir a algo gravado e do interesse de se criar videotecas. Mas a maioria dos documentos projetados não passa então de emissões didáticas em sentido estrito, isto é, respondendo à intenção de instruir, concebidas e organizadas "textualmente" nessa finalidade: são emissões informativas em sentido amplo, grandes reportagens, trechos dos jornais televisivos ou, às vezes, emissões de vulgarização científica. Reinseridos num contexto escolar, reutilizados pontualmente no quadro de uma disciplina e de um tema com uma classe de nível determinado, esses documentos não poderão senão constituir um dos elementos do material de aprendizado do aluno.

Pois seria errado achar que esse material bastará para suscitar os aprendizados esperados. Sabemos, por exemplo, que a taxa de retenção da informação apresentada num programa de televisão é baixa; apesar da extensão das campanhas de informação e do número de mapas apresentados nos jornais televisivos durante a Guerra do Golfo, uma maioria ignorava se o Iraque tinha ou não acesso ao mar... Esse exemplo é provavelmente caricatural, mas, nessas condições, por que diabos obstinar-se a avaliar uma emissão de televisão educativa em função dos mesmos critérios escolares de um curso? Com o risco de ter de afirmar que essa emissão, no fim das contas, ensina pouca coisa... A utilização de um documento desse tipo requer, para ter um mínimo de eficiência, um enorme trabalho de integração e de exploração cuja responsabilidade sempre incidirá sobre o docente. 
Notas

1. 'Definiremos o lugar de interação social como 'a área de cooperação' na qual a atividade específica à qual é articulada a realidade da linguagem se desenvolve; trata-se portanto de um conceito muito geral, abrangendo particularmente os diferentes tipos de instituições e aparelhos ideológicos da sociedade, mas outras áreas de exercício das práticas cotidianas." (Bronckart et al. 1985, p. 33)

2. Considera-se de fato que qualquer mensagem, além de seu conteúdo, comporta um aspecto relacional importante que poderíamos muito bem esquematizar da seguinte forma: de que modo vemos nosso interlocutor e de que modo the comunicamos isso; quais relações mantemos com nosso próprio discurso e como o exprimimos.

3. No quadro de nossa atividade de ensino na Faculdade de Psicologia e das Ciências da Educação da Universidade de Genebra, concentramos nossas pesquisas sobre o banco de videogramas de educação ao consumo franceses produzido pelo Bureau Information des Consommateurs, ingleses (a série inglesa Get it right), ou, enfim, holandeses (por exemplo o filme Wat verkoopot je me nou? ([O que você compraria agora?]).

4. Essa análise que identifica dois pólos - o didático e o socioeducativo - não leva em conta um gênero $n$ ovo, os produtos informáticos lúdicos e educativos que constituem uma parte importante de um mercado em desenvolvimento. Tais produtos, freqüentemente classificados sob o rótulo de edutainment (neologismo constituído a partir das palavras inglesas education e entertainment), parecem conseguir o que a televisão educativa nunca conseguiu: conciliar prazer e aprendizado, lazer e estudos.

Two specific forms of pedagogical mediated communication: Instructional and socio-educational communication

ABSTRACT: The author analyses the main concepts of the different types of pedagogical mediated communication. He tries to demonstrate that discourse seems to be one of the most important concepts in analysing these forms of pedagogical mediated communication. He distinguishes two main forms that could be considered as the poles of a taxonomy, and characterizes each of them by their main features related to: contents; aims and goals; target-public; curriculum; assessment; the social interaction scene; the material, human, institutional and socio-cultural frame of reference etc. Finally, he shows that such a distinction is a way to provide guidelines for mediated communication based training and teaching. 
Bibliografia

BAKHTIN, M. Esthétique de la création verbale. Paris, Gallimard, 1984.

BRONCKART, J.-P. et alii. Le fonctionnement des discours. Neuchâtel, Delachaux et Niestlé, 1985.

JACQUINOT, G. Cinéma et pédagogie. Paris, PUF, 1977.

MEUNIER, J.-P. e PERAYA, D. Eléments pour une analyse sémio-pragmatique des communications audi-scripto-visuelles. Bruxelas, De Bœck, 1993.

VANDEVELDE, L. Aider à devenir. Paris, Nathan Labor, 1982. 